\title{
Technological Evolution: Two Suggested Concepts
}

\author{
Geoffrey Fishburn \\ The University of New South Wales, Sydney, Australia 2052 \\ *Corresponding Author: G.Fishburn@unsw.edu.au
}

Copyright (C) 2014 Horizon Research Publishing All rights reserved.

\begin{abstract}
In introducing the concept of "exaptation" Gould and Vrba argued that it can often be gainful to introduce new ways ("revised taxonomies") of ordering and describing phenomena. In this paper two such are suggested with respect to technological change. The first involves a distinction between what are defined here as 'inside' and 'outside' complexity, and a suggested scheme of their co-evolution. The second points to the need for and usefulness of recognition of the corollary to the well-known phenomenon of 'locking-in', that which is characterised here as 'locking-out'.
\end{abstract}

Keywords Technology, Complexity, Locking-In

Terms in themselves are trivial, but taxonomies revised for a different ordering of thought are not without interest. (Gould and Vrba [1])

\section{Introduction}

Sometimes, there is a gain to be had from the naming of a concept, especially when the phenomena underlying it have been long present but not "seen." My purpose here is to argue, in the spirit of Gould and Vrba in their introduction of the concept of "exaptation," the more explicit recognition and discussion of two such similarly useful concepts: the first (as will be noted) is not altogether new, but is in need of further exploration and illustration; the second, it is suggested, has been overlooked, largely by default. Both, we claim, could prove of use in the narrative of technological evolution. ("Exaptation," whilst originating in biological science, has since found useful application in describing an aspect of the evolution of technology -- see Dew, Saraswathy, Venkataraman [2], although simpler yet more powerful illustrations of the phenomenon can, I believe, be given than are provided there).

\section{2. "Inside" and "outside-" Complexity}

W. Brian Arthur [3] posed the question: Why Do Things Become More Complex? Arthur's answer (which, in brief, is the elaboration of "subsystems [and] sub subsystems" driven by technological demands, competitive forces, or other exogenous requirements) is illustrated with reference to the development of the turbojet engine and the administrative structure of the modern university (to which we could add, since there is so little difference nowadays, the modern corporation). Each alike exhibits "growth in complexity," but of a particular sort which I shall designate here as "inside-complexity," to distinguish it from, in order to explore its relationship with, that of "outside-complexity." These terms, as "Inside Complexity" and "Outside Complexity", appear to have been first introduced by Harold W. Lawson [4] in the context of computer languages and systems. The application made here is far wider. Similarly, and slightly later, Francis Heylighen [5] explored ideas not unlike, at least in broad detail, those discussed here. Jürgen Jost [6] employs notions which he defines as:

"External complexity measures the amount of input, information, energy obtained from the environment that the system is capable of handling, processing. Of course, for our purposes, it is important that this can be measured as an entropy - and therefore, terms like "energy" need some qualification when employed in this context. In this sense, external complexity is data complexity.

Internal complexity measures the complexity of the representation of this input by the system. In this sense, internal complexity is model complexity." (p. 71)

There is some relationship between our "inside-complexity" and Jost's Internal complexity, but his analysis and that presented here serve two different purposes and address two fundamentally different problems: our "outside-complexity" refers to the interface between the technology (allowing a broad definition of that term) and its environment, which may itself exhibit -- and it makes no difference to what is said here -- any degree of External complexity.

Consider first the turbojet example. The cockpit of a modern jet aircraft presents an array of instruments which report not only data necessary for the pilot to know (wind speed, altitude and orientation, for example), but the state of the many "subsystems and sub subsystems" of the aircraft. There was a time when few, if any, such instruments were required. To expand Arthur's second case: the modern corporation, whether public or private, comprises subdepartments and subsubdepartments which make 
interaction with it by the outsider (and often, the insider as well) difficult. The days when an enquiry could be referred to someone "just down the corridor" or "across the office" have generally long gone, surviving only in the small-scale enterprise.

In both cases we see that there has been a growth of inside-complexity (Arthur's point), but with a corresponding growth in outside-complexity. The growth in inside-complexity is not, as Arthur is at pains to point out, necessarily open-ended. Nor, more importantly, is that of outside-complexity: computerization has necessarily assisted in holding down the growth of cockpit instrumentation, for example, and in making (in theory at least) the corporation more accessible to the outsider.

But reductions in outside-complexity, which tend to occur discreetly rather than continuously, come at a cost: they require a corresponding further increase in inside-complexity. Figure 1, which is meant to be suggestive rather than rigorously descriptive, illustrates this process.

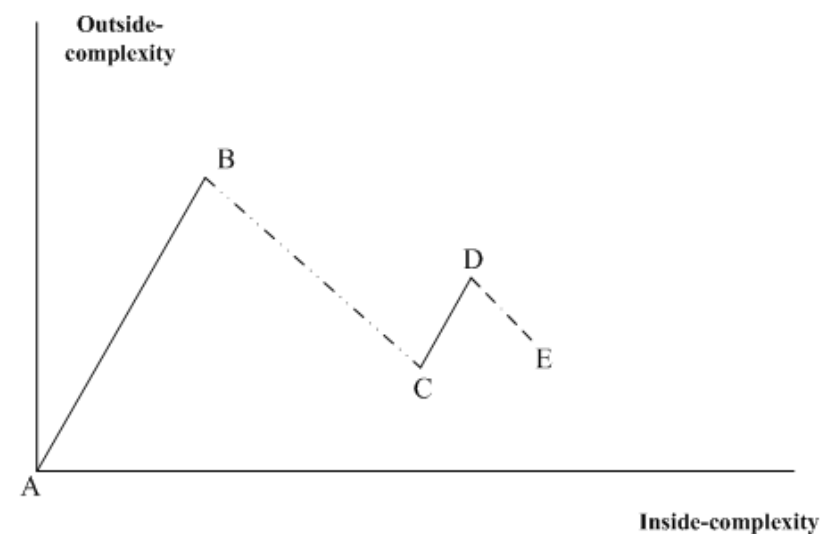

Figuer1. Suggested pattern of coevolution of inside-and outside-complexity

Measuring inside- and outside-complexity by some suitable and compatible means and representing these on the horizontal and vertical axes respectively, we show from A to $\mathrm{B}$ growth initially in both types of complexity. But between $\mathrm{B}$ and $\mathrm{C}$ there is a fall in outside-complexity with, necessarily, an increase in inside-complexity. From C, the process of joint growth in complexities starts over again. (The relative positions of $\mathrm{C}$ and $\mathrm{D}$ suggesting what might also possibly be observed: $\mathrm{C}$ is above $\mathrm{A}$ "things are never as simple to use as they once were" and D is below B "things are never allowed to get more complicated to use than they once were allowed to." Change may well in practice be far less continuous than is suggested here along the segments $\mathrm{AB}$ and $\mathrm{CD}$.)

The rationale behind Figure 1 is as follows. Let us suppose, for the sake of argument, that inside-complexity could grow indefinitely. This might not always be strictly true, with the weight of growing inside-complexity leading to collapse of development of the technology. It is not the issue of relevance here; the discontinuity which is suggested at $\mathrm{BC}$ is the one of principal interest at this point. Our primary concern here is, what could motivate a movement from B to $\mathrm{C}$ ? What forces could motivate the diversion of resources from increasing inside-complexity (A to B), whether that has been occurring deliberately or not, to reduction in outside-complexity (B to C)?

To answer this I turn to consideration of the separate driving forces behind inside- and outside-complexity. These are not wholly captured by the familiar technology-push/demand-pull distinction, although this can serve as a starting-point. With respect to inside-complexity, the desire to solve technical problems as they arise, and the natural desire for improvement ("higher", "faster"), will result in the proliferation of those "subsystems [and] sub subsystems" which for Arthur characterized the development of (inside-) complexity. With respect to human systems ("corporations," generically speaking) we can add the often-observed factor of uncoordinated duplication, more often driven by emulation than by any purely "rational" forces.

Growth in outside-complexity most often accompanies growth in inside-complexity ${ }^{\mathrm{i}}$, as is suggested by the movement $\mathrm{AB}$ in Figure 1. This appears to be a "natural" state of affairs. The corresponding "unnatural" state of affairs, when it occurs, is the movement BC. This imposes a cost (in capital and time) additional to that already being borne in the movement $\mathrm{AB}$, so we must naturally enquire as to why this should occur. Here, elements of "demand-pull" now come into play.

Simplicity is often prized largely for its own sake, or as an underlying principle: "form follows function" and "ornamentation is a crime" were the guiding motivations of the Bauhaus (1919-1933), that movement in architecture and design which laid the foundations of the modernist design aesthetic. There is, however, a more mundane, if ultimately very powerful, factor at work which has "demand-pull" elements: consumers/users will, eventually, resist those products or processes which they find too difficult to operate, or to integrate with existing systems, or for which the possibility of error in operation becomes unacceptably high.

A technology which becomes too difficult for the human subject to operate, or which requires too much time in order to learn how to operate properly, also runs an increased risk of error in operation. Humans, on the whole, need good reasons to be persuaded that time should be spent in learning anything new, and are certainly averse to the possibility of error in operation. Another way of making the same point is to regard the technology and the human subject as comprising two components of the same system, so that now the argument can be cast simply in terms of the familiar concept of "system compatibility." However we choose to express the reasons for it, there is a limit to human tolerance of outside-complexity, and those technologies which go beyond this will fail in the marketplace. For all its overuse, the modern cliché "user friendly" does have some operational content, and ever more so as less time can be devoted to mastering the intricacies of a given technology. Commercial success, ultimately, depends as much on 
making it easy to have a product or process do what it can do, as in what it can do in itself.

Account must also be taken of factors which might, in addition to those already mentioned, govern the speed of movement along $\mathrm{AB}$, or the timing of the event $\mathrm{BC}$. It can happen, in some instances, that inside-complexity is increased at a rate which is greater than that prompted by simple "technology push" with respect to the product or process itself -- we think here of computerized features in vehicles designed to lower polluting exhaust emissions, or similarly, those designed to lower greenhouse gas emissions from manufacturing. Likewise, the reduction in outside-complexity -- the movement BC -- will often be more readily undertaken the greater the awareness, as has indeed been the case in recent decades, of the needs of users who have below-average eyesight, hearing, manual dexterity, or even, for those who are otherwise "able," technical familiarity ${ }^{\text {ii }}$. Sometimes, too, it might be the degree of entrepreneurial flair, in seeing the competitive advantage to be had from a reduction in outside-complexity, which will determine whether the move $\mathrm{BC}$ is made sooner rather than later.

\section{Examples}

Of the many examples which could be given of the movement from $\mathrm{B}$ to $\mathrm{C}$, four such, in historical order, are now briefly made.

The Dewey Decimal Classification System (1876) brought some order, and a degree of added inside-complexity, to the library. Its degree of complexity has grown with revisions which have reflected the growth in specialisations and subspecialisations, including many fields not envisaged at the time of its creation. For the user of this particular technology ("the library"), outside-complexity is represented by the catalogue system, which has changed (speaking generally) from shelf-lists, to book entries, to card indexes, to the present on-line electronic catalogues (which are themselves of varying degree of complexity). Each reduction in outside-complexity, and most notably the last, required an increase in inside-complexity.

Hydraulic automatic transmission, marketed as "Hydra-Mastic drive," was first introduced by General Motors (Oldsmobile) in 1940. As a standard feature, or sometimes only an optional extra, it was soon adopted by other manufacturers, with notably more alacrity in the United States than in Europe. This innovation made the technical side of driving a vehicle considerably easier for many, and enabled growth of the market.

The TV "remote control," the forerunner of a now-ubiquitous technology, had a long prehistory but was first developed in its recognizably "modern" form by the BBC in the late 1970s (the sedentary viewer was soon to be further accommodated by the presetting of functions, such as vertical and horizontal hold, which had previously required some degree of manual dexterity and external adjustment -- again, requiring an increase in inside-complexity). The success of the TV remote control required that all further developments in this field (stereo-players, VCRs. DVD player/recorders, and the like), as well as those in quite unrelated areas (such as garage doors), be henceforth manufactured with the degree of inside-complexity necessary to enable remote control.

The Graphical User Interface [GUI] is now so accepted that a younger generation can well wonder at a time when it was necessary to actually $d o$ something in order to use a computer. And yet, it was so, within the living memory of many. Nor was that time in the distant past (even by today's standards). In this respect, it is worth quoting at length the remarks of Umberto Eco [7]:

"I asked above whether fountain pens were Protestant. Insufficient consideration has been given to the new underground religious war which is modifying the modern world. It's an old idea of mine, but I find that whenever I tell people about it they immediately agree with me.

The fact is that the world is divided between users of the Macintosh computer and users of MS-DOS compatible computers. I am firmly of the opinion that the Macintosh is Catholic and that DOS is Protestant. Indeed, the Macintosh is counter-reformist and has been influenced by the ratio studiorum of the Jesuits. It is cheerful, friendly, conciliatory; it tells the faithful how they must proceed step by step to reach -- if not the kingdom of Heaven -- the moment in which their document is printed. It is catechistic: The essence of revelation is dealt with via simple formulae and sumptuous icons. Everyone has a right to salvation.

DOS is Protestant, or even Calvinistic. It allows free interpretation of scripture, demands difficult personal decisions, imposes a subtle hermeneutics upon the user, and takes for granted the idea that not all can achieve salvation. To make the system work you need to interpret the program yourself: Far away from the baroque community of revelers, the user is closed within the loneliness of his own inner torment.

You may object that, with the passage to Windows, the DOS universe has come to resemble more closely the counter-reformist tolerance of the Macintosh. It's true: Windows represents an Anglican-style schism, big ceremonies in the cathedral, but there is always the possibility of a return to DOS to change things in accordance with bizarre decisions: When it comes down to it, you can decide to ordain women and gays if you want to.

Naturally, the Catholicism and Protestantism of the two systems have nothing to do with the cultural and religious positions of their users. One may wonder whether, as time goes by, the use of one system rather than another leads to profound inner changes. Can you use DOS and be a Vande supporter? And more: Would Celine have written using Word, WordPerfect, or Wordstar? Would Descartes have programmed in Pascal?"

These were, however actually recent, only "early days": to those who now regularly use them, touch-screen ("gesture") and voice-activated systems make even mouse-operated, 
drag-and-drop, systems seem hopelessly "manual" by comparison. iii Playful (of course) though his words might be, Eco expresses the basic point which I am making about outside-complexity: "DOS is Protestant, or even Calvinistic. It allows free interpretation of scripture, demands difficult personal decisions, imposes a subtle hermeneutics upon the user, and takes for granted the idea that not all can achieve salvation. To make the system work you need to interpret the program yourself: Far away from the baroque community of revelers, the user is closed within the loneliness of his own inner torment.'

To summarise. Each of these developments entailed a successively massive increase in inside-complexity in order to achieve the desired reduction in outside-complexity. They, and others such, have had the cumulative effect of revising the traditional common users' belief that technology is of its very nature "hard to use," to the expectation that it will be "easy to use."

Each, moreover, demonstrates the "evolutionary" nature of technological progress, in the following sense. As Darwin first explained [8], and has since been formalized by Henry Plotkin [9] in the concept of "universal Darwinism" or the "Darwin machine", at the core of every evolutionary process, and which thus must necessarily enter into any "evolutionary" narrative, are Replication, Variation, and Selection. Along the segment $\mathrm{AB}$ in our schema Variation increases, with purposeful invention taking the role played by random mutation in nature. But whilst the "better mousetrap" will be sought and, when achieved, enjoy a temporary competitive edge it will be, we have argued here, at the expense of increased outside-complexity. Thus, whilst Selection will accompany the increase in Variation along $\mathrm{AB}$, it is the movement $\mathrm{BC}$ where the force of Selection will operate most strongly: it is here, rather than along $\mathrm{AB}$, that Schumpeterian "creative destruction" is seen. ${ }^{\text {iv }}$

\section{4. "Locking-out"}

Before I built a wall I'd ask to know what I was walling in or walling out, And to whom I was like to give offence.

--Robert Frost, Mending Wall

The concept of, and the forces which lead to, "locking-in" are now sufficiently well-known and generally accepted as not to require further elaboration here. Illustrations abound. But as the lines from Frost suggest, there are two aspects to every wall, and it is with respect to a neglected aspect (of technological change and development) that I deal here.

What in an historical perspective will appear as the synchronous replacement of many technologies with others following application of a new generic technology (e.g., electricity, digitalization), with the consequent introduction of new products and processes and often a re-ordering of industry structures, is what we know as a Schumpeterian "wave of creative destruction." In such cases, products and processes relating to the older displaced technologies such as manual typewriters, wind-up gramophones, horse-and-buggy transport, and the like will be retained in rare instances only for curiosity, museum pieces, or sentimental value, becoming increasingly difficult to service as their original supporting technological networks disappear. Such technologies are however better described as "displaced," rather than "locked out" in the sense, as will now be explained, in which this phrase is to be used here.

We also know that as well as being one of the new "displacing" technologies, what becomes "locked in" very often emerges from an initial array of two or more products or processes (which for short we shall designate here simply as "technologies"). What happens to those which do not "succeed," and, unlike the 'successful' technology which comes to be "locked in," enjoy little if any further development? Must we regard "what might have been" as a "counterfactual" or "virtual history"?

In many cases those technologies which "failed" in the sense of not being selected for further development and eventual lock-in did not do so for purely rational technological reasons -- the oft-cited cases of Beta video-recording technology and non-QWERTY keyboards will serve as examples here. Many such technologies could, like the competing and eventually dominant technology, have been developed further; but as funding, research attention, and the development of supporting systems went increasingly towards one technology, they were not. They were locked-out.

But just as no technology is necessarily permanently locked in -- although the growth of supporting systems and complementary technologies, not to mention the habituation of the human operator (learning and retaining the memory of the layout of a keyboard, or of a system of weights and measures, for instance) make "unlocking" difficult and costly -- so, no technology is necessarily permanently locked out. Some, such as whatever might have been the developments in the horse-drawn carriage before the advent of the internal combustion engine and the "horseless carriage", it is true, are unlikely to be ever seen; others -- and it is these on which we focus here -- which were once thought to have been permanently locked out have enjoyed a substantial, if of (perhaps only as yet) limited application and further development. "Locking-out" should not be thought of as deriving from simple passive neglect: to a large extent, those forces which lead to locking-in generate an opposite and equally strong reaction leading to locking-out. And just as "unlocking" can occur, so too can, for want of a better word, "reinstatement." Three examples of such are now given.

Medicine and antibiotics. The "golden age of antibiotics," which is now passing, saw less attention paid to the development of drugs from natural and traditional sources, it notwithstanding that penicillin, and its many adaptations and modifications never did more than was promised, that is, be antibacterial agents. Recent years have seen an increased interest in alternative sources, and not just with respect to antibacterial agents. Whilst we are right to be skeptical of the 
claims made for many of the so-called "complementary" and "natural" medicines, we should remind ourselves of the fact that few if any human ailments are truly "modern," even if the incidence of some is: generations before survived, often remarkably well, without the aid of "modern medicine." Once simply dismissed as being either meaningless or unnecessary, traditional and indigenous pharmacopoeias are again being consulted.

The airship. It would be an exercise in virtual history to speculate on what might have been the case had not a world war and the following growth in consumer affluence in the developed economies not occurred, but what we can say with certainty is that competition between sea and airship carriage, in the areas in which this was taking place (luxury transcontinental travel, and cargo carrying), came to an abrupt end on 6 May 1937 with the destruction of the Hindenburg. It was not the first such event, but it was one too many. Airship technology was locked-out, leaving the field clear for the less cost-efficient (at that time) aero technology. Military development and application of the airship were carried out by the US Navy during the Second World War but commercial application had largely ceased, and any thought of it largely abandoned. Recent decades, however, have seen a revival in interest in this technology, albeit with application less general than once envisaged.

Alternative energy sources. We do not need to be told of the increased attention in the present climate (figuratively and literally) to power sources alternative to fossil fuels. Some of those now being developed, such as wind and water, are "old," sometimes by millennia, whilst others, such as solar, geothermal, and biological (and problematically for many, nuclear) are "new" to varying degree. Whilst it is not necessarily true that "everything old is new again," we should not let pass without notice the fact that in 1908 the Ford Model $\mathrm{T}$ was introduced with the capacity to run on either ethanol or petrol ("gasoline"). That this was so should come as no real surprise, given the history of ethanol use in the US and its cheapness relative to gasoline; but Ford, as it turned out, was a year too late: the discovery and exploitation of new oil fields in Texas in 1907, with the subsequent fall in oil prices, soon began the era of the oil-based internal combustion engine.

That what has long been regarded as the "inferior" technology, but was not at the time really so, is illustrated by the history of the internal combustion engine:

"The development of the automobile is often viewed as the direct consequence of the development of the internal combustion engine. Interestingly enough, most automobiles built around the turn of the century were not powered by internal combustion engines. In 1900, of the 4192 cars manufactured in the US, 1681 [40.1\%] were equipped with a steam engine, 1575 [37.6\%] with an electric motor, and 936 [22.3\%] with an internal combustion engine. During subsequent years, the balance tipped in favour of the internal combustion engine. However, during the beginning of the time of car manufacturing, it was not clear that the internal combustion engine 'would win out over other types. Clement
Adder's ... second airplane, the Avian III, completed in 1897, was powered by two small steam engines weighing $3 \mathrm{~kg}$. per horsepower, something that could not be attained with an internal combustion engine. For example, the airplane of the Wright brothers that flew in 1903 was powered by an internal combustion engine weighing $6 \mathrm{~kg}$. per horsepower.

In 1908 Henry Ford equipped his Model $\mathrm{T}$ automobile with a gasoline internal combustion engine; it was this model, of which there were more than 15 million built, that set the stage for the further development of the automobile." [10] (Italic and \% added here.)

Thus, with respect to the specific case of the internal combustion engine, steam and electricity were present as viable technologies from the outset. In the broader field of power-generation, wind- and water-power were exploited long before the present dependence on fossil fuels began, yet it is only in recent decades that serious large-scale research and development of these as sources of power alternative to fossil fuels has taken place, in some cases in macro-applications, such as providing power for factories and cities, and in others in micro-applications, in powering individual motor vehicles.

We see, from these few examples, a common pattern: the emergence, for a variety of reasons, of a single technology which becomes dominant and locked-in, with the accompanying locking-out of rival technologies. But locking-out is not necessarily any more permanent than locking-in. And whilst it may be objected that the development and exploitation of such older technologies now owes much to the much newer computer-technology, it can scarcely be doubted that such developments would be much further advanced today had not the original technologies been superseded, in use and development, by those which were, for a time, dominant and locked-in. However, it does not follow from the fact that cost is one factor (although rarely the only, and not necessarily the most important) in locking-in that "rehabilitation" of a locked-out technology will in its turn be easy or without great cost: Gert Jan Kramer and Martin Haigh [11] illustrate this with consideration of the switch from fossil to non-fossil energy sources.

\section{REFERENCES}

[1] Stephen Jay Gould, Elisabeth S. Vrba. Exaptation a missing term in the science of form, Paleobiology, Vol.8, No.1, 4-15. 1982.

[2] Nicholas Dew, S.D. Saraswathy. S. Venkataraman. The economic implications of exaptation, Journal of Evolutionary Economics, Vol.14, 69-84. 2004.

[3] W. Brian Arthur. Why Do Things Become More Complex?. Scientific American, May, 144. 1993.

[4] Harold W. Lawson. The Insides and Outsides of Computer-based System Complexity. In Jerzy Rozenblitz, 
Tony Ewing, Stephan Schulz (eds). Proceedings International Conference and Workshop in Engineering of Computer-based Systems (Monterey, California, March 24-28), IEEE Computer Society Press, Los Alamitos, CA, 1997.

[5] Francis Heylighen. The growth of structural and functional complexity during evolution. In Francis Heylighen, Johan Bollen, Alexander Riegler (eds). The Evolution of Complexity. The Violet Book of "Einstein Meets Magritte", Kluwer Academic Publishers, The Netherlands and VUB University Press, Brussels, Belgium, 1999.

[6] Jürgen Jost. External and internal complexity of complex adaptive systems. Theory in Blosciences, Vol,123, 69-88. 2004.

There are instances of growth in inside-complexity without corresponding growth in outside-complexity for some specific technologies, for example, that of (classical) musical instruments. The almost minimalist outside-complexity of the modern pianoforte - successor to a long line of keyed string instruments - has been so since the time of Beethoven; but variation, and to some extent, growth, in inside-complexity continues to the present day. A very similar story can be told with respect to most other classical musical instruments; their "acoustic" derivatives, with often little if any advance in outside-complexity, have exhibited increasing growth in inside-complexity.

"Technical familiarity" is often highly generational. We are familiar, for example, with those of an older generation who could not successfully programme a VCR, although they are otherwise able and competent, and often during their working life operated complex older technologies with great skill. For their grandchildren, programming and the whole "push-button" world see.ms so "natural" as to be beyond question.

"Convergence," in this case the bringing-together of many separate technologies sharing a common digital base, has posed a particular challenge to the reduction of outside-complexity. The latest generation of mobile ('cell') phones would not be able to sustain the outside-complexity of phone function, text messaging, camera operation, and the like, if each of these required its separate user interface. The solution, of allowing switching between different functions for the same user-interface, requires considerable additional inside-complexity.

However, ease of use via reduced outside-complexity, however important, will rarely be the sole criterion for Selection: peacetime market economies will have different selection criteria than wartime, and in general both will differ here from command economies, of whatever sort; as well, in some instances religious and historical factors will come into play.
[7] Unberto Eco. The Holy Wars: Mac vs. DOS. L'Espresso, September 30. 1994. Available in translation athttp://www.themodernword.com/eco/eco_mac_vs_pc.html (Retrieved 29 September 2013.)

[8] Charles Darwin. On the Origin of Species by Means of Natural Selection etc., London, John Murray, 1859.

[9] Henry Plotkin. Darwin Machines and the Nature of Knowledge, Harvard University Press Cambridge MA, 1994.

[10] Bryan Bunch, Alexander Hillmans. The Timetables of Technology. Simon \& Schuster (Touchstone Books), New York, 1994.

[11] Gert Jan Kramer, Martin Haigh. No quick switch to low-carbon energy, Nature, Vol. 462, 568-569. 2009. 